DOI: $10.1590 / 2316-4018386$

\title{
Sobre a perda da grandiloquência na literatura hispano-americana pós-noventa: notas sobre a des-representação do exílio em Lemebel e Bolaño Pablo Gasparini*
}

Caso queiramos resgatar um topos da literatura hispano-americana dos anos 1980 para pensar, a partir dele, algumas singularidades dessa literatura após a experiência autoritária que marcaram esses anos e incluindo nessas singularidades o tipo de leitor que parece estar sendo suposto na contemporaneidade, acho que poderíamos escolher, entre muitos outros, aquele do exílio. Isto porque o exílio não só se configura como um motivo (ou mais bem uma experiência) de representação recorrente nos anos 1980, mas também como um dado histórico da situação territorial de muitos escritores hispano-americanos nesse período. Também e fundamentalmente porque, ultrapassando a mera metáfora que faz de certa condição exílica a condição de toda escrita literária, o exílio constituiu a compelida situação de enunciação do próprio discurso literário sob o signo, como sabemos, de um contexto abertamente repressivo e totalitário.

Assumindo, portanto, a relativa arbitrariedade dessa escolha, mas também os dados que dizem respeito a certa pertinência dela, o objetivo deste breve artigo não é fazer uma recensão da representação do exílio no período referido (a década de 1980), mas considerá-lo operativamente como uma espécie de pivô que possa mostrar, a partir de sua própria representação e "des-representação" (tomo esta singular categoria de Libertella em Nueva escritura en Latinoamérica), certos sinais das guinadas (temático-formais) da literatura hispano-americana dentro de um período maior capaz de atingir nossos dias; guinadas essas que, sem querer estabelecer uma analogia ferrenha com a história política, veem-se sem dúvida afetadas, entre outros muitos fatores, pelo incipiente processo de democratização das sociedades latino-americanas.

Entendendo a guinada como um movimento que supõe menos um desvio que uma resignificação e aproveitamento de forças anteriores, tentaremos atentar não só para os cortes, mas também para as permanências e simultaneidades dos gestos e procedimentos escriturais que o pré-texto "exílio" possa nos revelar. Por fim, desejaria esclarecer que os autores e

* Doutor pela Universidade de São Paulo (USP), Pós-Doutor pelo IEL da Unicamp e Professor Doutor de Literatura Hispano-americana (USP). E-mail: pablogasparini@uol.com.br 
Pablo Gasparini

textos aqui citados ou comentados longe de pretender serem paradigmáticos (ainda que alguns o sejam) são meramente operativos para indicar, no breve espaço destas notas, uma série de observações específicas que possam, eventualmente, ser repensadas em textos e autores que, talvez em relação a algumas dessas observações, possam ser mais centrais ou relevantes.

Para começar, poderíamos fazer referência a uma reflexão pontual sobre o exílio no romance que Beatriz Sarlo (1987) considerou, em "Política, ideologia y figuración literaria", como representativo da literatura argentina da década de 1980: Respiración artificial, de Ricardo Piglia. No primeiro capítulo desse romance, organizado formalmente a partir da relação epistolar entre Emilio Renzi (um escritor que acaba de publicar o seu primeiro romance La prolijidad de lo real) e Marcelo Maggi (um historiador que teria fugido à cidade de Concórdia e que estuda os documentos de Enrique Ossorio, um ambíguo personagem membro do Salão literário de 1837 e, posteriormente, secretário privado de Rosas), podemos ler a seguinte colocação sobre o exílio e o exilado: “O que é o exílio senão uma forma da utopia? O desterrado é o perfeito homem utópico, escrevia Ossorio, escreve para mim Maggi, ele vive na constante nostalgia do futuro" (Piglia, 1983, p. 30) (tradução minha).

A afirmação, trazida por Renzi, evidencia a estrutura dialógica que organiza a narração (uma estrutura dialógica que, por meio de diferentes inflexões, determina também a organização dos restantes capítulos da primeira parte do romance) e faz do exílio o signo de uma temporalidade que colocando o presente entre grandes parênteses faz dele a expectativa de uma outra realidade (daí a dimensão do utópico) na qual, imaginariamente, seria possível aquilo que no presente é uma falta geradora de certa nostalgia. A torção de temporalidades que supõe a experiência do exílio ("nostalgia do futuro": uma frase que brilha já pela densidade de reflexão e pelo seu alto grau de elucubração) e a espessa rede de vozes que irá constituindo a trama do relato, não supõe - para sua compreensão - qualquer tipo de leitor, mas um leitor avezado nos jogos, sutilezas e procedimentos da literatura; um leitor que, como confessará o próprio Piglia em "Primera Persona", apreciará colocar à prova sua própria competência "narrar - diz Piglia - é jogar pôquer com um rival que pode olhar as tuas cartas" (Piglia, 2000, p. 145).

Para realizar uma confrontação radical que possa depois ser objeto de debate e de diferentes matizes, gostaria de contrapor a densidade conceitual que condensa, na breve citação que fizemos de Respiración artificial, a figura do exílio, com certo estreitamento ou redimensionamento do plano 
semântico/conotativo da mesma figura em "El rojo amanecer de Willy Oddo (o el rasguño letal de la doncella travesti)", uma das crônicas que compõem Loco afán: crônicas de sidario do chileno Pedro Lemebel (2000). No texto, que relata a morte e funeral de Willy Oddo, "um dos integrantes de Quilapayún, o grupo musical pioneiro do neofolclore revolucionário" (Lemebel, 2000, p. 112), se faz uma breve descrição da chegada do cantor após o seu exílio na Europa:

Porque na verdade, era esse um Chile desconhecido para o Willy tantos anos longe, cantando as mesmas músicas, a mesma "Plegaria del labrador" para gringos solidários. A mesma cantata de "O povo unido já mais será vencido" que tanto emocionava os italianos sorvendo macarrão com molho. Aquele "Potito embarrado" do Nino Luchín para a elegância francesa. As mesmas huijas de dor da Violeta Parra, mil vezes de estreia para a piedade europeia. O mesmo avião, os mesmos estádios e encontros de exilados entoando a cueca do retorno, comendo a empada sintética e a humita do milho congelado. Era isso muito pairar pelo mundo, como a pomba vermelha expulsa da arca que nunca encontrava a sua ilha. É depois, depois do dilúvio, recém regressado, depois de tanto cantar o martírio chileno, topar com esta morte de tango de página policial, de briga de rua. Esta morte sem ideologia, de uma outra partitura musical, feita bolero pelo álcool e pela euforia das altas horas da noite. Porque o Willy nunca imaginou que esse sábado a cidade levava um aguilhão no decote. (id., p. 113) (tradução minha)

A passagem de "nostalgia do futuro" para a procacidade das imagens sobre o exílio que pontuam o que teria sido a experiência do exilado Willy (remitida a uma série de aparentes lugares comuns sobre essa experiência: "a mesma cantata", "as mesmas huijas de dor", "a cueca do retorno", etc.) revela, em uma primeira leitura, aquilo que é mais evidente: o diferente contexto de escrita de ambos os relatos. Decerto, a emergência da experiência do exílio no contexto de escrita de Respiración artificial (lembremos que Piglia foi recorrentemente incluído como um daqueles escritores que teriam sofrido um "exílio interior") parece revestir a figura do exílio da solenidade própria de um vívido objeto de reflexão. Já a legitimação da voz narrativa a partir de certa atitude dessacralizadora daquilo que o narrador de Estrella distante, de Roberto Bolaño chamará de "triste folclore do exílio" (Bolaño, 1996, p. 35) pode ser compreendida, em primeira instância, pelo mero fato da crônica de Lemebel ser escrita, tal como é datado no próprio texto, no "Santiago postnoventa", isto é, quando o exílio político tem perdido a sua contemporaneidade para passar a ser objeto, quiçá, de 
Pablo Gasparini

uma reavaliação crítica de suas possibilidades enquanto matriz geradora de relatos.

Contudo, menos que atentar para as diferentes representações dessa experiência (nos casos específicos que estamos trabalhando, de matéria de reflexão para certo gesto que tenta desfazer as marcas usuais de sua representação assinalando, dessa maneira, certa "descontinuidade" que poderia ser entendida sob a figura da kenosis desenvolvida pelo Harold Bloom em La angustia de las influencias) ${ }^{1}$ o importante seria aqui atentar para os diferentes imaginários de trabalho literário que essas variadas figurações sobre o topos exílio deixam entrever.

Nesse sentido, o caráter reflexivo que o trabalho literário assume em Respiración artificial, de Piglia, será entendido por Sarlo, como já foi dito, como prototípico do papel dos "discursos da literatura" durante o último processo militar argentino. Segundo Sarlo:

diante da pobreza imposta dos sentidos e da univocidade de explicações (romances como aqueles do Piglia) criaram um espaço rico de sentidos e de explicações que deram conta da ambiguidade e da dificuldade em uma sociedade opaca. (Sarlo, 1987, p. 40-1) (tradução minha)

A preferência pelo romance de Piglia (significativa se pensarmos que 1980 é também o ano de aparição de um outro romance medular da literatura argentina contemporânea: Nadie nada nunca, de Juan José Saer) ${ }^{2}$ possa talvez ser explicada pelo fato de a leitura de Sarlo ser paralela à própria maneira na qual Piglia pensa as relações entre literatura e Estado. De fato, a colocação de Beatriz Sarlo parece coincidir com uma outra do próprio Piglia na qual o escritor, fazendo uso da inflexão abertamente crítica de sua voz, avalia o papel da literatura e de sua própria produção. Assim, em "Una trama de relatos", Piglia faz da literatura uma força capaz de des-

\footnotetext{
${ }^{1}$ A kenosis é um movimento mais ambivalente que o clinamen ou a tesera e supõe o gesto de desfazer ou esvaziar o poema precursor mediante uma perda voluntária e premeditada da continuidade (Bloom, 1991, p. 104). Ainda que a proposta de Bloom esteja referida pontualmente à poesia, tentamos especificar com esta perspectiva o conceito de des-representação que Libertella propõe em Nueva escritura en Latinoamérica como uma desmontagem crítica que determinados textos da literatura latino-americana fariam dos modelos vanguardistas anteriores.

${ }^{2}$ De fato, a convicção crítica que em Sarlo faz da ambiguidade do discurso literário um claro valor político e moral parece não atingir a escrita de Saer, que, mesmo apelando também em Nadie nada nunca para o caráter ambíguo do discurso literário, não ocupará o lugar paradigmático reservado a Piglia. Decerto, como o assinala Julio Premat em La dicha de saturno, enquanto Respiración artificial "tornou-se, rapidamente, o emblema de uma escrita criptografada e de uma representação problemática da ditadura (...) o romance de Saer (e em particular a sua visão da Argentina atual), passou despercebido" (Premat, 2002, p. 390) (tradução minha).
} 
centrar a narração que o Estado imporia como eixo aglutinador da sempre multiforme e variada correnteza dos discursos. Diz Piglia:

Há um circuito pessoal e privado da narração. E há uma voz pública, um movimento social do relato. O Estado centraliza essas histórias; o Estado narra. Quando o poder político é exercido, está sempre sendo imposta uma maneira de contar a realidade. Mas não há uma história única e excludente circulando na sociedade. (Piglia, 2000, p. 43) (tradução minha)

Dessa maneira se, como é dito em um recente estudo sobre a literatura argentina das últimas décadas do século XX, "Respiración artificial é um romance que falando (e escrevendo) de literatura e história fala (e escreve) de política" (Bracamonte, 2007, p. 454), é porque o jogo de sentido que provocaria o discurso literário estaria voltado, segundo Piglia e Sarlo, ao questionamento das certezas do discurso centralizador e monoglota do Estado; uma convicção sobre as funções da literatura que a própria Sarlo, no artigo citado, justifica através de uma oportuna citação de Minima moralia na qual Adorno reflete sobre a tarefa do pensamento:

Devem ser propostas perspectivas que desloquem e tornem estranho o mundo, que revelem o seu ser, com os seus escolhos e as suas fissuras, tão distorcido e pobre como aparecerá, algum dia, à luz messiânica. Ganhar essas perspectivas, sem veleidade e sem violência a partir de um contato sentido com os objetos. Tal é a tarefa do pensamento. (Adorno apud Sarlo, 1987, p. 158) (tradução minha)

Diante dessa tarefa (moral?) para a literatura, resulta evidente que a crônica de Lemebel aparece marcada sob o traço de certa intranscendência e isto não só porque no plano da representação a (desmontada) épica do exilado é oposta ao caráter circunstancial (e sexual) de uma morte por acaso (no dia de sua volta para o Chile, Willy Oddo é assassinado por um travesti com o qual tentava negociar uma relação sexual: uma "morte sem ideologia" que causa o desconcerto das "Juventudes Comunistas" que cantando, no dia do funeral, a Internacional não sabem "em qual frase, em qual verso combativo daquela gloriosa marcha" "pôr a emoção... onde acentuar a raiva, onde apontar o assassino do Willy" (Lemembel, 2000, p. 112), mas porque, centralmente, é um outro, acredito (e mesmo por se tratar - ao menos em uma primeira instância - de uma crônica) o imaginário sobre a literatura que o texto supõe.

Se pensarmos que, refletindo sobre a literatura latino-americana das últimas décadas, Reinaldo Laggada (2007) sustenta que determinados autores dessa literatura "estão inscritos na tradição de uma literatura ao mesmo tempo complexa no plano da forma e indiferente aos valores (...) 
Pablo Gasparini

(da) potencia, da altura, da sobre-abundancia de sentido - ou, segundo termos do próprio Pitol, a 'grandeza de tom', a 'muito complexa construção'" (Laggada, 2007, p. 30), resulta evidente que Lemebel, mesmo não fazendo parte do corpus proposto por Laggada (centralmente focado no argentino César Aira, no peruano radicado no México Mario Bellatin e no brasileiro João Gilberto Noll), compartilharia ao menos os traços de aspiração a certa "condição da instantânea" e certa "condição da improvisação" (id., p. 15) que as crônicas de Lemebel, mesmo pelo fato de serem crônica (isto é uma escrita emergida - aparentemente - da velocidade e imediatidade de um fato atual e público: aqui o assassinato ao acaso de Willy Oddo), colocariam como condição de sua enunciação.

Sem tempo aqui de trabalhar como na esteira de certa tradição hispano-americana (pensemos nas crônicas dos modernistas) a apropriação estética ou "literaturização" do gênero "crônica" desvirtua o seu pretenso caráter objetivo e faz possível, no caso de Lemebel, alguns dos efeitos que Lagadda assinala como paradigmáticos de certa literatura latino-americana da década de 1990, desejaria ressaltar como certo afrouxamento da "muito complexa construção" (complexidade esta da qual ainda é depositária Respiración artificial, talvez perpetuando a aspiração monumental dos grandes romances hispano-americanos da década de 1960) também é assinalado por Gustavo Pellón (1996) na hora de descrever certos desenvolvimentos em corpus já mais canônicos, como aqueles da "novela testimonio" ou do romance histórico. Pellón contrapõe, no caso do testemunho, a construção mais solta de Gallego (1983) se comparada com Biografía de un cimarrón (1966) e ressalta, pelo lado do romance histórico, a atitude de des-mitificação dos grandes relatos e figuras nacionais (Pellón se referirá centralmente a El general em su laberinto (1989).

Contudo, voltando para a zona inicialmente apontada, aquela que de alguma maneira estamos tentando balizar com as "post-noventistas" crônicas de Lemebel, é notório que aquela perda da "grandeza de tom" (categoria que, inerente à já indicada redimensão formal da narrativa, Lagadda toma do mexicano Pitol) pode ser pensada, talvez, a partir da revisão daquele assentamento do trabalho literário a partir dos supostos poderes políticos/reflexivos da literatura e isto não só porque, ainda com as contradições inerentes a todo processo, a redemocratização tentaria definir um outro modelo de Estado, mas também porque, como assinala de forma rotunda Minelli (2006), a própria literatura tem passado a desempenhar um "papel subalterno (...) na gestão das identidades" (Minelli, 2006, p. 55) e isto em grande parte, como o assinala Quintana (2001), devido aos efeitos de "uma sociedade massmediatizada que teria já definitivamen- 
te 'colonizado' para utilizar os termos de Jameson, a memória cidadã". (Quintana, 2001, p. 15)

Decerto, esse novo cenário envolve não só novas concepções de leitor e de autor, mas também o redimensionamento do espaço onde essa interação é materializada e supõe, aliás, novas perspectivas de representação. Dessa maneira, a relação com o leitor quiçá seja menos compreendida a partir do exclusivamente reflexivo (que fazia do leitor aquele "jogador de pôquer" figurado pelo Piglia) que mediante, como sustenta Lagadda, "a indução de um transe" (Lagadda, 2007, p. 15) que não menospreza os possíveis códigos comuns suscitados pelo massmedia. Por outro lado, as novas figurações de autor não só apontam para certa ocasional espetacularização dessa figura, mas também, na esteira de Puig, certa - como assinala Minelli - ocultação da formação literária para sublinhar o vínculo com a cultura massiva, ou, na esteira de um Copi (segundo Minelli "escritor-ator-travesti-humorista gráfico" (Minelli, 2006, p. 99), certa multidimensionalidade artística, evidente no próprio Lemebel: artista plástico fundador, em plena ditadura chilena do "Colectivo de Arte Yeguas del Apocalipsis". Finalmente, essas novas concepções de leitor e de autor envolvem a criação e procura de novos espaços de leitura e de publicação, seja por meio das novas tecnologias seja pela interação direta com o social (como no paradigmático caso de Washington Cucurto e a editora Eloísa Cartonera na Argentina) e acenam, já no específico plano da representação literária, para novos sujeitos determinados muitas vezes em razão de sua marginalidade e gênero ${ }^{3}$, e, frequentemente, em razão da marginalidade de seu gênero.

Quiçá seja esse último um dos aspectos mais evidentes na crônica aqui tratada de Lemebel, pois é em definitivo o acaso sexual da morte de Willy Oddo o que descentra a épica romântica das "Juventudes Comunistas" no enterro do folclórico exilado recentemente repatriado. Desfocalização que bem poderia ser ilustrada com certa observação que o narrador de "El Ojo Silva" de Bolaño arrisca sobre a relação entre gênero e exílio na hora de comentar algumas fofocas sobre o protagonista desse relato:

Naqueles dias era comum dizer que o Ojo Silva era homossexual. Eu quero dizer: nos círculos de exilados corria esse rumor, que era um pouco manifestação de maledicência e um outro pouco uma nova fofoca que alimentava a vida um tanto chata dos exilados,

\footnotetext{
${ }^{3}$ Nesse sentido, Pellón (1996) aponta que "romancistas dos anos 1970 e 1980 tentaram (...) recontar Cem anos de solidão, mas para Mauricio Babilonia, Pilar Ternera ou Petra Cotes, ao invés do ponto de vista da oligarquia representada (embora charmosa) pelo ponto de vista da família Buendía” (Pellón, 1996, p. 281) (tradução minha).
} 
Pablo Gasparini

pessoas de esquerda que pensavam, pelo menos da cintura abaixo, exatamente como as pessoas de direita que se assenhoreavam naquele tempo do Chile. (Bolaño, 2001, p. 12) (tradução minha)

De fato, neste texto que faz parte do livro Putas asesinas (2001) a homossexualidade do exilado Mauricio Silva é considerada como um aspecto a contrapelo de certa (auto)representação do exílio, e configura um dos elementos que quebra a expectativa de um relato literalmente político sobre essa experiência pois o destino de Silva, como de alguma maneira aquele de Diego Soto em Estrella distante, acabaria demonstrando o acaso e a transnacionalidade da violência para além do específico terrorismo de determinado Estado (Soto termina os seus dias de felicidade familiar sendo esfaqueado por jovens neonazistas na cidade de Alicante enquanto Mauricio Silva se perde nas intrigas de uma cultura que se lhe revela como inevitavelmente alheia).

Contudo, tanto para completar a des-representação ou kenosis de certa retórica do exílio, quanto para marcar certa manutenção do imaginário literário que podia ser assentado nela, gostaria de citar um trecho de 2666 do próprio Bolaño, no qual Amalfitano (o "chileno errante" da segunda parte desse rabelaisiano e póstumo romance) responde certas questões dos críticos literários Norton e Pelletier:

Quando os críticos, já muitos mais benevolentes com a aparição de Amalfitano, perguntaram para ele o que estava fazendo na Argentina no ano 1974, ele olhou os críticos, olhou o seu coquetel Margarita e falou, como se já o tivesse dito muitas vezes, que no ano 1974 ele estava na Argentina pelo golpe de Estado no Chile, golpe que tinha obrigado ele a seguir o caminho do exílio. E depois desculpou-se pela forma um tanto grandiloquente de se expressar.

Todo acaba se grudando, falou, mas nenhum dos críticos deu muita importância para essa ultima frase.

- O exílio deve de ser algo terrível - falou Norton, compreensiva.

- Na realidade - falou Amalfitano- agora vejo o exílio como um movimento natural, algo que, a seu modo, contribui para abolir o que comumente é considerado o destino.

- Mas o exílio - falou Pelletier - está cheio de dificuldades, de pulos e rupturas que mais ou menos se repetem e fazem difícil qualquer coisa importante que a gente queira fazer.

- Precisamente aí reside - falou Amalfitano- a abolição do destino. E perdoem mais uma vez. (Bolaño, 2009, p. 156-7) 
A distância que vai de "nostalgia do futuro" à "abolição do destino" (isto é, de uma figura de certa predeterminação moral para uma outra que destaca o ganho de um presente liberado de toda prescrição ou "destino") não só marca a impostura de certa grandiloquência (ou, segundo Laggada/Pitol, aquela "grandeza de tom" que ressaltávamos a propósito de certo imaginário da literatura dos anos 1980) da qual Amalfitano pede desculpa, mas também a sua permanência, pois a guinada que significa Bolaño para a literatura hispano-americana está assentada também, se pensarmos principalmente em Los detectives salvajes - um romance "monumental" - no tão dito caráter reflexivo da literatura pigliana; caráter este que em Bolaño parece estar voltado menos para a confirmação de certos consensos representacionais sobre a experiência do exílio do que para o questionamento de certas zonas da instituição literária vislumbradas como sustentadoras do regime ditatorial (lembremos que em Nocturno de Chile, um sarau literário funciona num "belo" lar familiar que é também um centro de tortura do terrorismo de Estado).

Não é por acaso então que em "Los mitos de Cthulhu" Bolaño poupa Piglia (entre outros poucos nomes) de sua habitual e acirrada crítica aos escritores de língua espanhola "O que podem fazer Sergio Pitol, Fernando Vallejo e Ricardo Piglia contra a avalanche de glamour? Pouca coisa. Literatura" (Bolaño, 2002, p. 171). Um reconhecimento dos anos 1990 aos anos 1980 que, menos como sobrevivência do que como gesto precursor, Lemebel, por sua vez, marcaria com o poeta e antropólogo argentino Néstor Perlongher (a quem está dedicado, entre outros, a Loco afán) não só talvez pela comum inquietação política e genérica ou pela sua comum inclinação neobarroca, mas, centralmente, por aquela intenção perlongheriana de "sexualizar o trauma" que (arriscando uma leitura) faz com que na crônica trabalhada o assassino de um exilado político seja nada menos que "a noite cafiola e travesti".

\section{Referências bibliográficas}

BARNET, Miguel (1983). Gallego. Ciudad de La Habana: Letras Cubanas. (1975). Biografía de un cimarrón. México D.F.: Siglo Veintiuno.

BOLAÑO, Roberto (2009). 2666. Barcelona: Anagrama. (2002). El gaucho insufrible. Barcelona: Anagrama. (2001). Putas asesinas. Barcelona: Anagrama. (1996) Estrella distante. Barcelona: Anagrama.

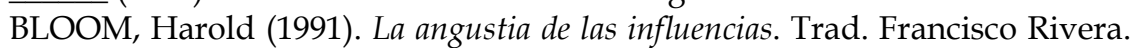
Caracas: Monte Avila. 
Pablo Gasparini

BRACAMONTE, Jorge (2007). Los códigos de la transgresión. Lengua literaria, lengua política y escritura contemporánea en la narrativa argentina. Córdoba: Editora de la Universidad Nacional de Córdoba.

GASPARINI, Pablo (2006). El exilio procaz: Gombrowicz por la Argentina. Rosario: Beatriz Viterbo.

LADDAGA, Reinaldo (2007). Espectáculos de realidad. Ensayo sobre la narrativa latinoamericana de las últimas dos décadas. Rosario: Beatriz Viterbo.

LEMEBEL, Pedro (2000). Loco afán: crónicas de sidario. Barcelona: Anagrama. LIBERTELLA, Héctor (1977). Nueva escritura en Latinoamérica. Caracas: Monte Avila.

GARCÍA MARQUEZ, Gabriel (1989). El general en su laberinto. Barcelona: Mondadori.

MINELLI, María Alejandra (2006). Con el aura del margen: cultura argentina en los '80/'90. Córdoba: Alción.

PELLÓN, Gustavo (1996). “The Spanish American novel: recent developments, 1975 to 1990". In: ECHEVARRÍA, Gonzales e PUPO-WALKER (Orgs.). The Cambridge history of Latin American literature. Cambridge: Cambridge University Press.

PERLONGHER, Néstor (1982). “Lamborguini, Carrera, Lambroguini: um 'nuevo' verso rioplatense?" Documento 0790. Archivo Perlongher, CEDAE. São Paulo: Unicamp.

PREMAT, Julio (2002). La dicha de saturno: escritura y melancolía en la obra de Juan José Saer. Rosario: Beatriz Viterbo.

PIGLIA, Ricardo (2000). Crítica y ficción. Buenos Aires: Seix Barral. (1983). Respiración artificial. Buenos Aires: Sudamericana.

QUINTANA, Isabel (2001). Figuras de la experiencia en el fin de siglo. Rosario: Beatriz Viterbo.

SARLO, Beatriz (1987). "Política, Ideología y figuración literaria". In: BALDERSTON, Daniel (Org.). Ficción y política: la narrativa argentina durante el proceso militar. Buenos Aires: Alianza Estudio. p. 30-59.

Recebido em maio de 2011.

Aprovado em julho de 2011.

\section{resumolabstract}

Sobre a perda da grandiloquência na literatura hispano-americana pós-noventa: notas sobre a des-representação do exílio em Lemebel e Bolaño

Pablo Gasparini

A partir de referências pontuais às diferentes representações do exílio em Respiración artificial, de Ricardo Piglia, Loco afán: crónicas de sidario, de Pedro Lemebel e 2666 e o conto "El Ojo Silva", de Roberto Bolaño, o artigo tenta ilustrar a passa- 
gem de certo imaginário político da literatura hispano-americana na década de 1980 para um outro imaginário que suporia a ressignificação de certas funções e especificidades do discurso literário dentro do processo de redemocratização das sociedades latino-americanas e do crescente fortalecimento da cultura de massas.

Palavras-chave: exílio, Lemebel, Bolaño, Piglia

About the loss of grandiloquence in Spanish American literature post-nineties: notes on the de-representation of exile in Lemebel and Bolaño

Pablo Gasparini

The aim of this article is to analyze the transition from the political comprehension of the Hispanic-American Literature on the ' 80 to another paradigm that involves specific changes on the functions and characteristics of the literary discourse due to the Latin-American democratization and the strengthening of the mass culture. For this aim, will be done references to the exile representations on Respiración artificial by Ricardo Piglia; Loco afán. Crónicas de sidario by Pedro Lemebel, and 2666 and the short story "El Ojo Silva" by Roberto Bolaño.

Key words: exile, Lemebel, Bolaño, Piglia

Pablo Gasparini - "Sobre a perda da grandiloquência na literatura hispano-americana pósnoventa: notas sobre a des-representação do exílio em Lemebel e Bolaño". Estudos de Literatura Brasileira Contemporânea, n. 38. Brasília, julho-dezembro de 2011, p. 97-107. 